\title{
Use of anti-gonadotropin-releasing hormone vaccines in African elephants (Loxodonta africana): A review
}

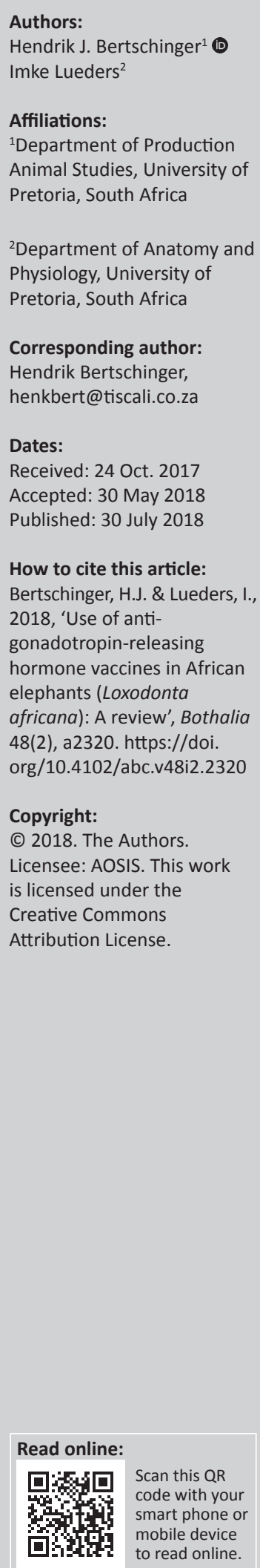

Background: Androgen-related aggressive behaviour and musth cause serious problems in captive African elephant bulls and often lead to human and animal injuries, and damage to property.

Objectives: To review the work carried out with anti-gonadotropin-releasing hormone $(\mathrm{GnRH})$ vaccines to control androgen-related behaviour and fertility in captive and free-ranging elephant bulls and the induction of anoestrus in elephant cows.

Method: In the first study, an anti-GnRH vaccine from Pepscan was tested in six bulls (four captive and two free-ranging). Once the vaccine Improvac ${ }^{\circledR}$ became available, the effect on behaviour, the reproductive organs and semen quality was tested. Improvac ${ }^{\circledR}$ was also used to attempt induction of anoestrus in elephant cows.

Results: The first study proved that aggressive behaviours are significantly associated with increased faecal androgen concentrations. Musth $(n=1)$ and aggressive behaviour $(n=2)$ were down regulated and correlated with a decline in faecal androgen concentrations. Aggression and musth could be controlled with Improvac ${ }^{\circledR}(600 \mu \mathrm{g})$, but were more consistent when the dose was increased to $1000 \mu \mathrm{g}$ administered every five to six months. The same dose down regulated testicular function and bulls $(n=17)$ were rendered infertile within 12 months after commencement of treatment. Initial attempts to induce anoestrous with $600 \mu \mathrm{g}$ in free-ranging elephant cows gave inconclusive results, but $1000 \mu \mathrm{g}$ in captive cows delivered five-monthly was successful.

Conclusion: The treatment of elephant bulls with Improvac ${ }^{\circledR}$ resulted in the successful downregulation of androgen-related behaviour and sperm production in captive and wild elephant bulls of various ages ( $\leq 34$ years). Preliminary studies to induce anoestrus in cows with Improvac ${ }^{\circledR}$ appear to be successful.

\section{Introduction}

\section{Musth in elephant bulls}

In the wild, age, social ranking and reproductive behaviour, the latter being androgen-dependent, are the three most important factors that determine the likelihood of a bull being able to mate with cows in oestrus. Hollister-Smith, Poole and Archie (2007:287-296), determined the paternity of calves born in Amboseli over a 30-year period. The authors showed that African elephant bulls (Loxodonta africana) that were 45 years and older sired $50 \%$ of all calves. They also showed that $75 \%$ of progeny were sired by bulls that were in musth at the time of mating. Although physical stature and strength are known to affect ranking, older bulls in musth are more likely to be afforded the chance to breed than non-musth bulls. The physiological signs of musth are (1) swelling of the temporal glands accompanied by thick mucoid exudates and (2) during the height of musth, urine dribbling (Ganswindt et al. 2010:506-514). Watery exudates from the temporal glands are seen in both sexes and all ages of elephants and are associated with excitement and frights (Bertschinger et al. 2008:257-328). Musth is accompanied by extremely high blood levels of testosterone (Kaewmanee et al. 2011:379-383). In free-ranging African elephants, the first signs of musth occur at about 25 years of age. In the absence of older dominant bulls, however, musth may occur at an earlier age. This is significant for bulls that are raised in captivity or translocated to reserves where there are no adult bulls present. In the wild, regular musth cycles, which are bull specific, only occur from about the age of 35 (Eisenberg, McKay \& Jainudeen 1971:193-225; Ganswindt et al. 2010:506-514).

\section{Aggression in elephant bulls}

Testosterone is not the only hormone controlling aggressive behaviour in animals. In laboratory animals, the wiring for dominance and behaviour is established early in perinatal life (Yu \& Shi 
2009:44-49). Testosterone acts by stimulating existing pathways from puberty onwards. Very likely, the same applies to elephant bulls. Not all bulls in musth with blood testosterone levels of $\geq 100 \mathrm{nmol} / \mathrm{L}$ behave aggressively towards humans, objects such as vehicles or other animals. Life experiences and the influence of adult elephants certainly play an important role in these intelligent animals. In bulls that are raised in captivity under hands-on conditions, the keepers or grooms take on the role of the dominant individuals. Many bulls, in particular, start to challenge this hierarchy as they approach puberty. During this period, testosterone concentrations start increasing, and bulls become more assertive, difficult to handle and, sometimes, aggressive. Following a number of incidents in South Africa and Zimbabwe, the so-called problem bulls were euthanised. In larger reserves, African elephant bulls seldom pose a problem, but in small reserves, encounters with bulls in musth are probably more frequent. Reportedly, lone elephant bulls learn to chase tourist vehicles. Inevitably, when accidents happen, the elephants and not the drivers are deemed to be at fault (Bertschinger \& Sills 2013:85-107).

The need for a method to control musth and aggressive behaviour in free-roaming 'problem bulls' and captive, handson elephant bulls to avoid animal welfare relevant practices is thus clear. Rarely, surgical castration has been performed in Asian elephants in Western zoos. Because of the intraabdominal location of the testicles, this procedure is not without risk to the animal. Castration was performed on a young bull in Zimbabwe (currently kept in South Africa). This animal, although in his 20s now, has remained in direct contact for more than 18 years without problems (R. Hensman, Adventures with Elephants, June 2010, pers. comm.). For free-ranging bulls, gonadectomy would require experienced veterinarians and heavy equipment. Therefore the method is not cost-effective and, of course, is irreversible. Earlier attempts to control musth and aggressive behaviour in elephant bulls using antiandrogens (Niemuller, Brown \& Hodges 1998:1018-1029) and the gonadotropin-releasing hormone $(\mathrm{GnRH})$ agonist leuprolide (De Oliveira et al. 2004:70-76) were met with limited success. The development of commercial anti-GnRH vaccines to control reproduction and associated behaviour in domestic and some wildlife species offered the opportunity to test two different formulations in elephant bulls in southern Africa.

\section{Ethical considerations}

The project was approved by the Animal Ethics Committee of the University of Pretoria (Permit No. V016-12).

\section{Anti-gonadotropin-releasing hormone vaccines \\ Mode of action}

The hypothalamic hormone, GnRH, controls the release of follicle stimulating hormone (FSH) and luteinising hormone (LH) from the pituitary gland. Simplified, FSH largely regulates spermatogenesis, and LH controls testicular

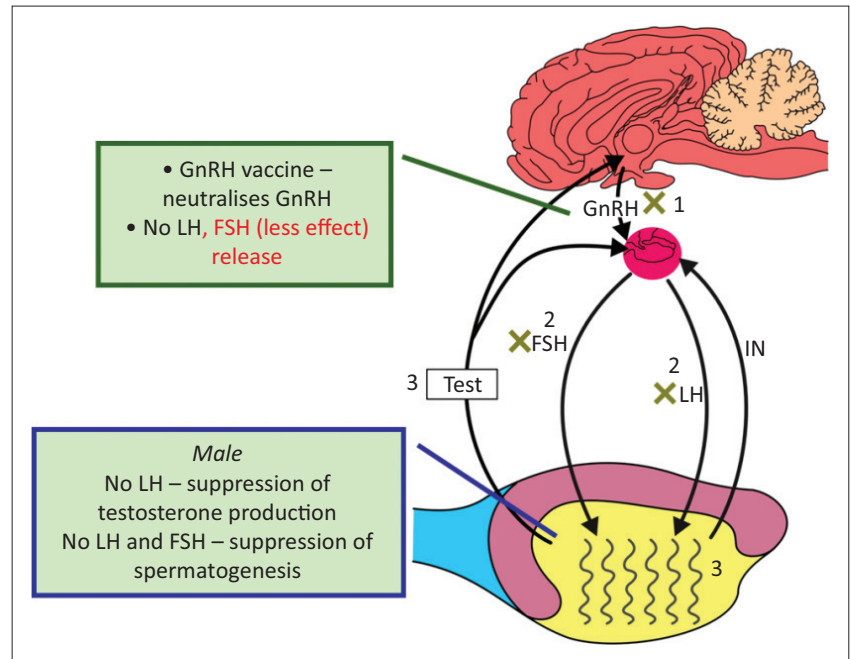

Source: Modified from Bertschinger, H.J. \& Sills, E.S., 2013, 'Contraceptive applications of $\mathrm{GnRH}$-analogs and vaccines for wildlife mammals of southern Africa: Current experience and future challenges', in E.S. Sills (ed.), Gonadotropin-releasing hormone (GnRH). Production, structure and function, pp. 85-107, Nova Science Publishers Inc., New York, (eBook) $\mathrm{LH}$, luteinising hormone; FSH, follicle-stimulating hormone; Test, testosterone; IN, inhibin.

FIGURE 1: Endocrine control of testicular function and mode of action of antigonadotropin-releasing hormone $(\mathrm{GnRH})$ vaccines. Anti-GnRH antibodies neutralise endogenous GnRH (1); down-regulate LH (2) and FSH (2) release; spermatogenesis (3) and testosterone synthesis and release (3).

testosterone secretion. The control mechanisms are intricate and involve feedback mechanisms (Figure 1). Anti-GnRH immunocontraceptive vaccines specifically target $\mathrm{GnRH}$ as a result of anti-GnRH antibodies, which are formed in response to treatment. The antibodies neutralise endogenous $\mathrm{GnRH}$, which leads to a lack of stimulation of the hypophysis and thus no secretion of FSH and LH and, as a result, downregulation of gonadal function. The anti-GnRH vaccines have the potential to be used in both sexes to control reproduction and associated behaviour.

\section{Anti-gonadotropin-releasing hormone vaccine in other species}

Anti-GnRH vaccines were first developed for the immunocastration of cattle (D'Occhio 1993:345). One of the main reasons for further development of these vaccines was to control boar taint in pork as an alternative to surgical castration (Dunshea et al. 2001:2525-2535). In stallions, similar vaccines have been used to control androgen-related behaviour and testicular size (Dowsett et al. 1996:228-235; Janett et al. 2009:88-102; Malmgren, Andresen \& Dalin 2001:78-83; Turkstra et al. 2005:247-259). In this respect, the anti-GnRH vaccine Improvac ${ }^{\circledR}$ (registered for use in pigs; Zoetis Animal Health, South Africa) has been shown to be highly effective in young stallions (Birrell 2017:1-49). The same vaccine was also successfully employed to control the oestrous cycle and thus fertility in mares (Botha et al. 2008:548-554; Schulman et al. 2012:1-3). Reversibility was demonstrated in 47 of 51 mares, with a return to normal cyclicity within two years of last treatment (primary and one booster). Anti-GnRH vaccines have also been used in a number of other species to control fertility or androgenrelated behaviour. Examples are sheep (Janett et al. 2003:291-299), rats and dogs (Ferro et al. 2004:73-86), cats (Levy et al. 2004:1116-1130), feral swine (Killian et al. 
2006:378-384), camels (Ghoneim et al. 2012:1102-1109), goats (Godfrey 1996:41-54), white-tailed deer (Miller, Johns \& Killian 2000:266-274) and bison (Miller, Rhyan \& Drew 2004:725-730).

\section{Use of anti-gonadotropin-releasing hormone vaccines in elephant bulls First anti-gonadotropin-releasing hormone vaccine study in elephant bulls}

In 2003, the first study to control aggressive behaviour and musth in African elephant bulls with an anti-GnRH vaccine was carried out on four captive and two free-ranging bulls in southern Africa (De Nys et al. 2003:17, 2010:8-15). Only one of the four captive bulls was showing aggressive behaviour at the onset of treatment. The three others had shown periods of aggressive behaviour previously. One freeranging bull was in musth and the other one was aggressive and had destroyed a number of the facilities on the reserve. A modified GnRH-tandem-dimer-ovalbumin conjugate vaccine (Pepscan Systems; Lelystad, Netherlands) combined with CovaccineTM (Covaccine B.V.; Utrecht, the Netherlands) as adjuvant was used. Three captive and two free-ranging bulls were treated three times at intervals of three to seven weeks. A fourth captive bull was first treated using a different adjuvant (Montanide ISA 51VG, Seppic; Paris, France), but owing to incomplete injection on account of high viscosity, a fourth treatment using CovaccineTM was administered. Faecal androgen concentrations were monitored on consecutive days prior to treatment and at intervals after each vaccination. A validated assay, known to reflect blood testosterone concentrations in African elephant bulls, was used to monitor faecal androgen concentrations (Ganswindt et al. 2002:27-30; Palme \& Möstel 1994:111-117). Behaviour was also recorded and related to faecal androgen concentrations. Aggressive behaviour before vaccination was positively correlated with faecal androgen concentrations.
The behaviour of the captive aggressive bull improved after the fourth vaccination. Both free-ranging bulls showed an improvement in behaviour. Signs of musth ceased 10 days after the first vaccination and aggression in the other bull ceased after the third vaccination (Figure $2 b$ ). Furthermore, at commencement of the study, faecal androgen concentrations were significantly higher in the two aggressive bulls than in the three non-aggressive bulls. Figure 2a shows the response of the faecal androgen concentrations to the anti-GnRH vaccine in the non-musth free-ranging aggressive bull Thembo. Overall, the results were encouraging. The three non-aggressive captive bulls in Zimbabwe (Imire Rhino and Wildlife Conservation) remained tractable for the duration of the four-month study. Monitoring of these bulls continued after the end of the trial. One bull (age 27 years) entered musth 10 months after the last vaccination. During this musth period, he killed a rhino bull on the same property and was subsequently euthanised. The two other elephant bulls (ages 28 and 18 years) received no further treatments, but became problematic in 2007 and 2009, respectively, when they were treated with Improvac ${ }^{\circledR}$. After resumption of five-monthly treatments, no further problems were reported. The two bulls are currently 38 and 28 years old, and although musth should have occurred by now, the anti-GnRH vaccine appears to have suppressed this state completely.

The free-ranging aggressive bull (Thembo, age 18 years) was moved to a sanctuary in 2005 where treatment with the Pepscan vaccine was resumed and retreated every five to six months. Since 2006, he has been treated regularly with Improvac ${ }^{\circledR}$. He is currently 35 years old and remains tractable.

\section{Additional bulls treated with Improvac ${ }^{\circledR}$ vaccine in southern Africa}

Since the first trial in 2003, more than 45 additional bulls, mostly captive, but some wild, were treated with

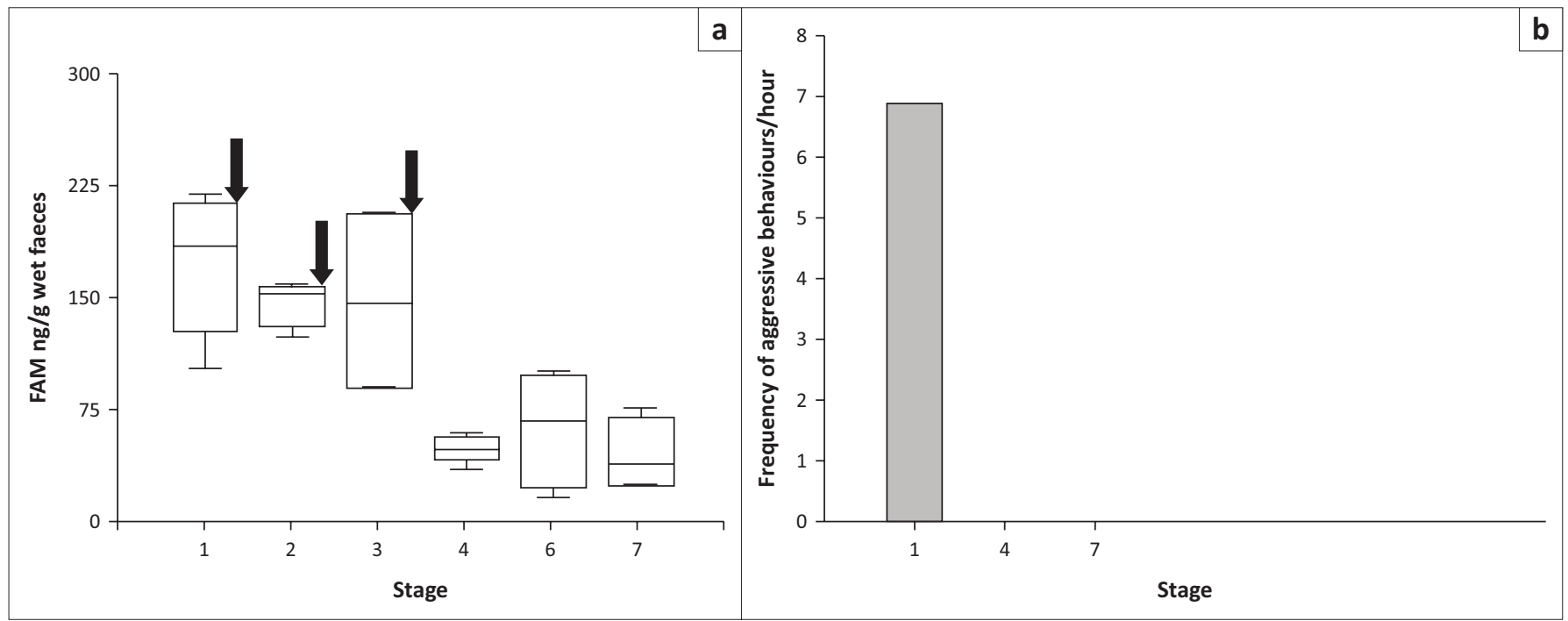

Source: Modified De Nys, H.M., Bertschinger, H.J., Turkstra, J.A., Colenbrander, B., Palme, R. \& Human, A.M., 2010, 'Vaccination against GnRH may suppress aggressive behaviour and musth in African elephant (Loxodonta africana) bulls - A pilot study', Journal of the South African Veterinary Association 81, 8-15

FIGURE 2: (a) Box and whisker graphs showing the grouped concentrations of faecal androgen metabolites (FAM) for free-ranging aggressive bull Thembo before (Stage 1 ) during (Stages 2 and 3 ) and after (Stages 4, 5 and 6) anti-gonadotropin-releasing hormone (GnRH) immunisations. (b) Frequency of aggressive behaviours before (Stage 1) and after (Stages 4 and 7) anti-GnRH immunisations. 
Improvac $^{\circledR}$ to control aggressive behaviour and musth (Bertschinger et al. 2009:71; Bertschinger \& Sills 2013:85107). Indications for treatment were always the presence of one or more bulls on the property showing bull-related dominant and aggressive behaviour, which sometimes resulted in serious injuries to elephant grooms. The initial dose tested was $600 \mu \mathrm{g}$ GnRH protein conjugate $(=3 \mathrm{~mL}$ Improvac $\left.{ }^{\circledR}\right)$. The primary treatment was followed by a booster five weeks later and with follow-up boosters every six months, or earlier if required, using the same dose. Some sanctuaries, however, reported bulls reversing earlier with this dose. As a result, the dose was empirically increased to $1000 \mu \mathrm{g}(5 \mathrm{~mL})$ of GnRH protein conjugate with intervals of five to six months between boosters. The increased dose has produced much more consistent results.

Improvac ${ }^{\circledR}$ vaccine is now being used as a behavioural management tool rather than as an experimental drug. Consequently, monitoring of behaviour is carried out by owners or managers who are likely to have been subjective. Nonetheless, the number of serious incidents was reduced to zero and tractability was improved to such a degree that sanctuaries preferred to continue with vaccinations. Where the collection of blood samples has been possible, serum testosterone concentrations have either been very low or undetectable. Some examples are shown in Table 1.

\section{Does Improvac ${ }^{\circledR}$ affect the fertility of treated bulls?}

This question was addressed in a study carried out recently in South Africa (Lueders et al. 2017:1-21). A prospective group of 11 bulls (Group 1; nine captive and two wild) aged eight to 36 years, after the initial primary and first booster (five weeks later), were treated every five to seven months with Improvac ${ }^{\circledR}$ $(1000 \mu \mathrm{g})$ by deep intramuscular injection (i.m.). Prior to vaccination and six-monthly, the internal genital organs were examined by means of trans-rectal ultrasound, semen was collected and evaluated, and serum testosterone concentration was measured over a period of three years. Another six bulls aged 19-33 years, which had been treated for 5-11 years were subjected to a once-off examination as described above (Group 2; four captive and two wild). Behaviour of Group 1 bulls was monitored subjectively throughout.

There was a marked effect of the vaccine on all variables measured. Mean testicular diameter in Group 1 decreased from $13.3 \mathrm{~cm} \times 15.2 \mathrm{~cm}$ at the beginning to $7.6 \mathrm{~cm} \times 10.2 \mathrm{~cm}$ after more than five treatments (Figure 3). Mean sizes of the ampullae, prostate and seminal vesicles also decreased significantly. Percentage normal sperm decreased from 33.8\% to $93.8 \%$ prior to vaccination to only $0.7 \%-26.0 \%$ after three treatments and no normal sperm were found after four or more treatments. At the same stage, very few or no sperm

TABLE 1: Examples of the effect of anti-gonadotropin-releasing hormone vaccine treatment on serum testosterone (T4) concentrations (vaccine changed to Improvac in 2006).

\begin{tabular}{|c|c|c|c|c|c|c|c|c|c|c|c|c|c|c|}
\hline Bull & Date & $\begin{array}{c}\mathrm{T} 4 \\
\mathrm{nmol} / \mathrm{L}\end{array}$ & Date & $\begin{array}{c}\mathrm{T} 4 \\
\mathrm{nmol} / \mathrm{L}\end{array}$ & Date & $\begin{array}{c}\mathrm{T} 4 \\
\mathrm{nmol} / \mathrm{L}\end{array}$ & Date & $\begin{array}{c}\mathrm{T} 4 \\
\mathrm{nmol} / \mathrm{L}\end{array}$ & Date & $\begin{array}{c}\mathrm{T} 4 \\
\mathrm{nmol} / \mathrm{L}\end{array}$ & Date & $\begin{array}{c}\mathrm{T} 4 \\
\mathrm{nmol} / \mathrm{L}\end{array}$ & Date & $\begin{array}{c}\mathrm{T4} \\
\mathrm{nmol} / \mathrm{L}\end{array}$ \\
\hline Thembo & BT 2003 & 27.10 & 2005 & 0.00 & 2005 & 0.80 & 2005 & 1.30 & 2007 & 0.00 & 2008 & 0.00 & 2014 & 0.00 \\
\hline Makavhuze & BT 2003 & 34.6 & 2014 & 0.01 & - & - & - & - & - & - & - & - & - & - \\
\hline Mana & BT Jul 12 & 32.4 & Feb 13 & 0.05 & - & - & - & - & - & - & - & - & - & - \\
\hline Sharu & BT Jul 12 & 61.3 & Feb 13 & 0.05 & - & - & - & - & - & - & - & - & - & - \\
\hline Michael & BT Jul 12 & 6.4 & Feb 13 & 0.11 & - & - & - & - & - & - & - & - & - & - \\
\hline
\end{tabular}

BT, before treatment.

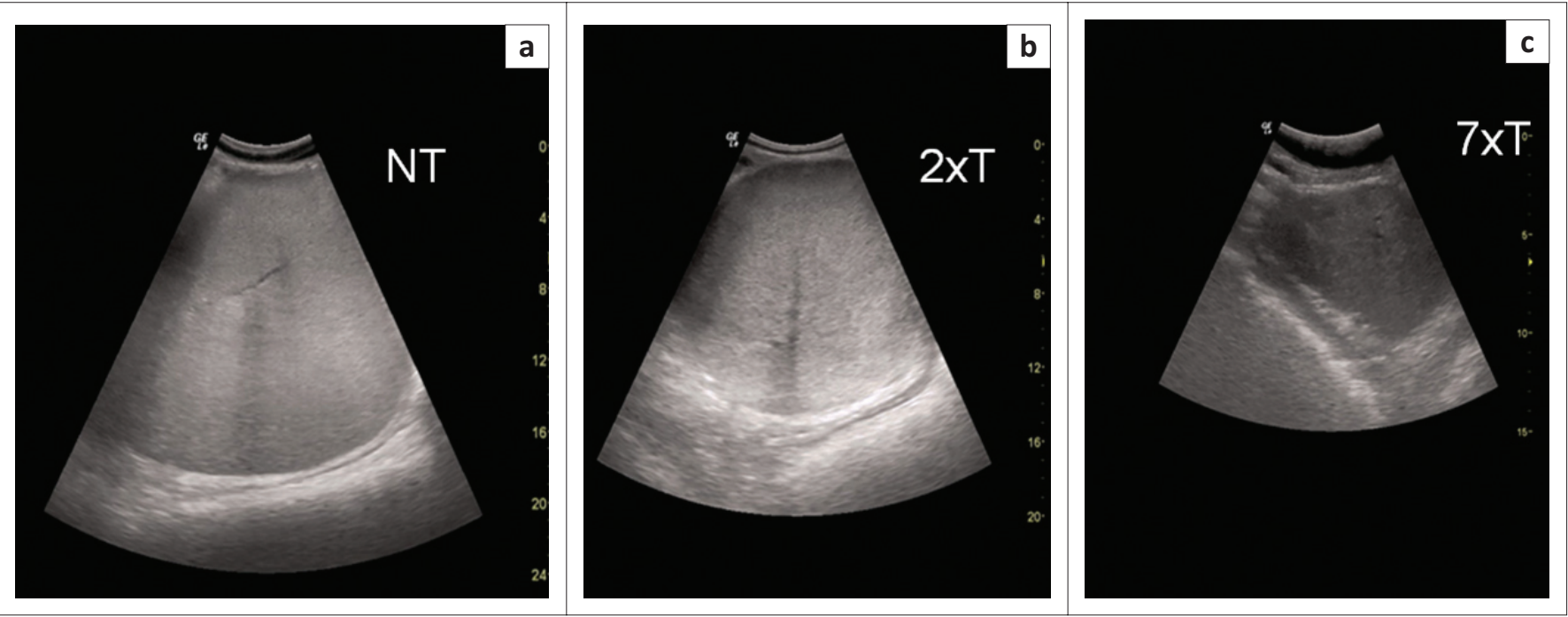

Source: Modified from Lueders, I., Young, D., Maree, L., Van der Horst, G., Luther, I., Botha, S. et al., 2017, 'Effects of GnRH vaccination in wild and captive African elephant bulls (Loxodonta africana) on reproductive organs and spermatogenesis', PLoS One 12(9), e0178270, 1-21. https://doi.org/10.1371/journal.pone.0178270 NT, No treatment; T, Treatments.

FIGURE 3: Trans-rectal ultrasound images showing the relative size and appearance of the testis of the same bull (a) before, (b) after two treatments, six months, and (c) after seven treatments, 24 months. 
were present. The period required to reach infertility was approximately 12 months. Serum testosterone concentrations were below baseline in all captive bulls six months after start of treatment, whereas in wild bulls this was only reached after 12 months. Group 2 bulls had small internal genital organs and very little or no seminal fluid could be recovered, which contained no sperm. Serum testosterone concentrations were at baseline or undetectable.

\section{Side effects of Improvac ${ }^{\circledR}$ vaccine Other species}

Improvac ${ }^{\circledR}$ is registered for pigs where extensive safety and efficacy studies were performed before registration. It is also used extensively as an extra-label drug in mares and stallions to control sex hormone-related behaviour. In other species, injection site reactions, depending on the anti-GnRH vaccine, can include acute inflammation with swelling and pain and abscesses (white-tailed deer, Curtis et al. 2008:6879; horses, Botha et al. 2008:548-554; Dowsett et al. 1996:228235). This is dependent on the species and especially the vaccine used. Vaccines consist of the specific antigen(s) and an adjuvant. The latter helps to mount an immune response to the vaccine antigen and is also largely responsible for the side effects. Theubet et al. (2010:459-467) observed a febrile reaction accompanied by reduced food intake after vaccination of calves with Bopriva ${ }^{\circledR}$ (Zoetis). This resolved within one to three days. Short-lived febrile reactions are common to many vaccines and are indicative of a good immune response. The same observations were made in mares (Botha et al. 2008:548-554) and stallions (Birrell 2017:49) treated with Improvac ${ }^{\circledR}$.

\section{Injection site reactions in elephant bulls}

Injection sites reactions are sometimes seen in elephants. Lueders et al. (2017:1-21) reported an incidence of 3.4\% in a total of 84 vaccination events. These reactions were stiffness or lameness and occasionally localised swelling, which resolved spontaneously and did not require treatment. One particular elephant sanctuary regularly observed stiffness in the injected leg in two bulls and one cow (S. Hensman, Adventures with Elephants, December 2016, pers. comm.).

\section{Behavioural effects in elephant bulls}

De Nys et al. (2010:8-15) clearly demonstrated the positive relationship between aggressive behaviours and faecal androgen concentrations. Using regular treatments of Improvac $^{\circledR}$, musth was prevented for 4 to 15 years in $\geq 45$ captive African elephant bulls (Bertschinger \& Sills 2013:85107). Mounting behaviour between captive bulls also ceased after treatment with Improvac (Lueders et al. 2017:1-21). Treated bulls seldom attempt to mount cows in oestrus, although they do show interest. Contrary to Europe and North America, breeding of African elephants in captivity is seldom required in southern Africa and is in fact banned according to the National Norms and Standards for the
Management of Elephants in South Africa (2008:39) for elephant sanctuaries. Thus, reproductive behaviour and fertility of captive elephants is not required in South Africa. Where there are two or more bulls in a captive facility, it is important to either treat all bulls or carefully select the bulls for treatment according to age and size. If neglected, problems may arise as a result of potential changes in the hierarchy because untreated bulls may challenge down-regulated conspecifics.

In the wild, however, there are other considerations. Between musth periods, bulls are calmer, socialise with other bulls and often encounter cows during their daily movements, but do not specifically seek them out. In musth, this changes with bulls becoming more solitary, leaving their home range, and they travel large distances to seek out cows in oestrus. Essentially down-regulated bulls likely behave like inter-musth bulls and most certainly they will be less assertive and dominant towards bulls of similar size and possibly smaller stature. When treating individuals in a population of wild bulls, similar to captive bulls, hierarchy also needs to be considered. Doughty et al. (2014:88-96) recorded a change in hierarchy after the 43-year-old dominant bull was treated with Improvac ${ }^{\circledR}$. They suggest that the second oldest of nine 9-21 year-old untreated bulls became the dominant bull in the population. The treated bull, however, was still able to cope with challenges from other bulls. In contrast, three adult bulls were treated with Improvac for seven years on Karongwe Game Reserve and no hierarchical or dominance problems were noted between them or untreated younger bulls. In another study, a 15-yearold bull had separated from his natal herd, but following Improvac $^{\circledR}$ he reverted to his herd associated behaviour (Lueders et al. 2017:1-21).

Additional positive aspects of anti-GnRH treatment are effects on fence-breaking (reported above) and damaging of trees. In the same study, one wild and one captive bull frequently broke fences prior to treatment. This behaviour ceased after two treatments. Two adult wild bulls ( $>30$ years) developed the habit of excessively damaging trees on a reserve in KwaZulu-Natal. Following two Improvac ${ }^{\circledR}$ treatments, the incidence of tree damage was markedly reduced. About six months after discontinuation of treatment, the behaviour returned, but has reduced once again after further treatments (M. Toft, Wildlife Veterinarian, November 2017, pers. comm.). Owners and managers should, however, take note that the improved behaviour was based on a small sample size $(n=4)$. Responses to vaccination may vary individually and are strongly dependent on age, social factors and life experiences of the individual.

\section{Effects on growth rate}

Table 2 shows growth rates (measured by shoulder height) of African elephant bulls treated with Improvac ${ }^{\circledR}$ for one to three years. Age at first treatment had no significant effect on annual growth and varied from $1.5 \mathrm{~cm}$ to $9.5 \mathrm{~cm}$ a year (unpublished data). In Table 3, the change in shoulder 
TABLE 2: Age, height increase and average annual increase in 11 Group 1 bulls from the first to the final examination.

\begin{tabular}{|c|c|c|c|c|c|c|}
\hline \multirow[t]{2}{*}{ Bull } & \multicolumn{2}{|c|}{ First examination } & \multicolumn{2}{|c|}{ Last examination } & \multicolumn{2}{|c|}{ Height increase $(\mathrm{cm})$} \\
\hline & Age (years) & Height $(\mathrm{cm})$ & Age (years) & Height $(\mathrm{cm})$ & For period & Per year \\
\hline Nduna (C) & 8 & 210 & 9 & 212.0 & 2.0 & 2.0 \\
\hline Gambo (C) & 10 & 224 & 13 & 237.0 & 13.0 & 4.3 \\
\hline Shaka(C) & 15 & 230 & 18 & 269.0 & 39.0 & 13.0 \\
\hline Clyde (C) & 17 & 240 & 20 & 268.5 & 28.5 & 9.5 \\
\hline Mukwa (C) & 22 & 292 & 25 & 310.0 & 18.0 & 6.0 \\
\hline Thaba (C) & 22 & 290 & 25 & 308.0 & 18.0 & 6.0 \\
\hline Duma (C) & 23 & 297 & 25 & 306.0 & 9.0 & 4.5 \\
\hline Harry (C) & 24 & 290 & 27 & 294.5 & 4.5 & 1.5 \\
\hline Namib (C) & 24 & 274 & 27 & 287.0 & 13.0 & 4.3 \\
\hline Mashatu (W) & 15 & 247 & 17 & 263.0 & 16.0 & 8.0 \\
\hline Jabulani (W) & 34 & 302 & 36 & 319.0 & 17.0 & 8.5 \\
\hline
\end{tabular}

Source: Modified from Lueders, I., Young, D., Maree, L., Van der Horst, G., Luther, I., Botha, S. et al., 2017, 'Effects of GnRH vaccination in wild and captive African elephant bulls (Loxodonta africana) on reproductive organs and spermatogenesis', PLOS One 12(9), e0178270, 1-21. https://doi.org/10.1371/journal.pone.0178270

C, captive; W, wild; cm, centimetres.

TABLE 3: Change in shoulder height, left and right tusk length over 4 years in four captive bulls during ongoing treatment with Improvac ${ }^{\circ}$ vaccine at Elephant Whispers.

\begin{tabular}{|c|c|c|c|c|c|c|c|c|c|c|c|}
\hline \multirow[t]{2}{*}{ Name } & \multirow{2}{*}{$\begin{array}{l}\text { Year of first } \\
\text { treatment }\end{array}$} & \multicolumn{4}{|c|}{ First measurement (2014) } & \multicolumn{4}{|c|}{ Second measurement (2018) } & \multicolumn{2}{|c|}{ Mean annual increase } \\
\hline & & Age (years) & Height $(\mathrm{cm})$ & Left tusk $(\mathrm{cm})$ & Right tusk (cm) & Age (years) & Height $(\mathrm{cm})$ & Left tusk $(\mathrm{cm})$ & Right tusk (cm) & Height $(\mathrm{cm})$ & Tusk (mm) \\
\hline Thembo & 2003 & 30 & 325.5 & 34.65 & 20.20 & 34 & 334.0 & 41.34 & 25.79 & 2.13 & 154 \\
\hline Shawari & 2008 & 21 & 263.0 & 14.96 & 16.93 & 24 & 298.0 & 23.03 & 24.25 & 8.75 & 193 \\
\hline Ziziphus & 2008 & 19 & 261.0 & 13.39 & 13.39 & 22 & 271.0 & 16.92 & 20.39 & 2.50 & 132 \\
\hline Medwan & 2008 & 19 & 255.0 & 17.72 & 15.75 & 22 & 298.5 & 21.65 & 19.09 & 10.86 & 91 \\
\hline
\end{tabular}

Source: A. Kotze, Elephant Whispers, April 2018, pers. comm.

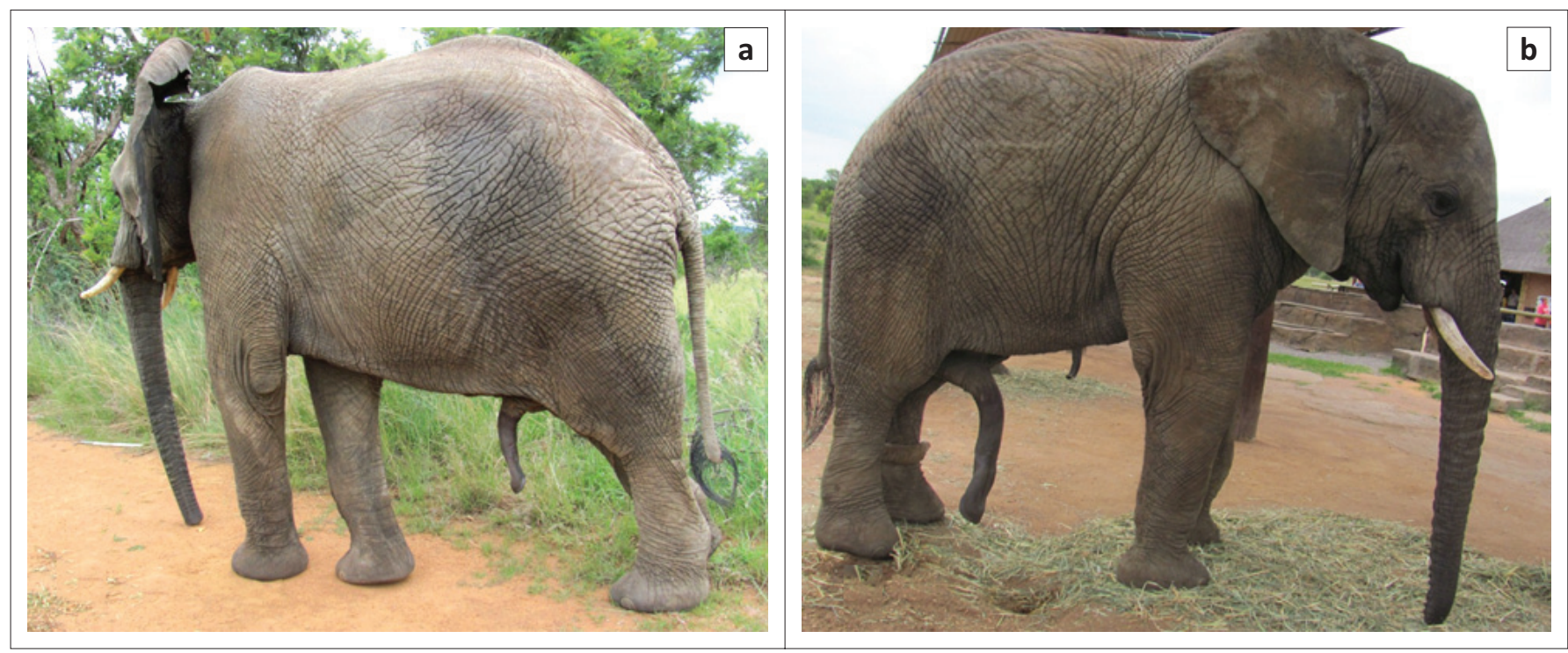

Source: Modified from Bertschinger, H.J. \& Sills, E.S., 2013, 'Contraceptive applications of GnRH-analogs and vaccines for wildlife mammals of southern Africa: Current experience and future challenges', in E.S. Sills (ed.), Gonadotropin-releasing hormone (GnRH). Production, structure and function, pp. 85-107, Nova Science Publishers Inc., New York, (eBook)

FIGURE 4: Effect of six-monthly Improvac treatments for 32 months (a) on the size of the extruded penis. Bull (b) was a similar age and untreated.

height and tusk length over a 4-year period in four captive bulls during ongoing Improvac ${ }^{\circledR}$ treatment is shown (A. Kotze, Elephant Whispers, April 2018, pers. comm.). The growth rates (shoulder height) of the bulls in each table are similar to those described in the literature. However, age-related shoulder heights reported here are greater than those found in Amboseli (Lee \& Moss 1995:29-41) and other reserves (Shrader et al. 2006:40-48). Measurements of captive bulls reported in Tables 2 and 3 were carried out in standing animals. The two wild elephants (Table 2) were measured in lateral recumbency. Sizes reported for bulls in Amboseli and other reserves were determined using photographs or photogrammetry, respectively.
Improvac ${ }^{\circledR}$ treatment of two young (16-18 years of age) captive bulls for 32 months resulted in much smaller and shorter penises than a bull of similar age in the same facility (Figure 4; Bertschinger \& Sills 2013). The difference in size appeared to be the result of penile atrophy rather than suspended growth. The mean annual tusk (both tusks) growth rate for four captive bulls under ongoing Improvac ${ }^{\circledR}$ vaccine treatment was $142 \mathrm{~mm}$ (Table 3). Age appeared to have no effect. There are no references to tusk growth rate in the literature. G. Steenkamp (Faculty of Veterinary Science, University of Pretoria, April 2018, pers. comm.), who studied tusk defects in captive African elephants, observed an average annual growth rate of $75 \mathrm{~mm}$. 


\section{Reversibility in elephant bulls}

Improvac ${ }^{\circledR}$ vaccine was designed for use in male piglets and reversibility was not conclusively investigated. Early shortterm treatment of African elephant bulls with Pepscan antiGnRH vaccine resulted in reversal in at least three of the six treated bulls (De Nys et al. 2010:8-15). During the early use of Improvac ${ }^{\circledR}$, when a dose of $600 \mu \mathrm{g}$ was used, some bulls showed signs of behavioural reversal after five months or earlier. Hence, the dose was increased to $1000 \mu \mathrm{g}$ (Bertschinger \& Sills 2013:85-107). Despite the dose increase, bulls on long-term Improvac ${ }^{\circledR}$ treatment ( $>8$ years) may show minor changes in behaviour (exhibited as a reluctance to respond to commands) five to six months after the last booster (A. Kotze, Elephant Whispers, July 2013, pers. comm.), although at this stage peripheral testosterone concentrations are generally still very low. In Asian elephant bulls, anti-GnRH antibody titres start to wane around this time (Somgird et al. 2016:111-120) and, possibly, the behavioural changes are because of a few GnRH molecules that escape neutralisation. GnRH is known to induce certain sexual behaviours at the level of the brain in mammals (Kauffman 2004:794-806).

Treatment of a seven-year-old Asian elephant bull for six years appears to have resulted in permanent downregulation of testicular function after seven years (Lueders et al. 2013:611-619). One year after the first vaccination, no sperm could be observed in the ejaculate and the diameter of the testicles had decreased by $40 \%$. The penis stopped developing and remained at the size of a six-year-old bull. Four years after the cessation of treatment, the testosterone levels have remained at baseline (Lueders et al. 2014:611619). Reversal of androgen production and semen quality was assessed in four African elephant bulls (two captive and two wild elephants, 18 and 30 years, and 19 and 36 years old, respectively) treated with Improvac ${ }^{\circledR}$ for 2.5-3.0 years (Lueders et al. 2017:1-21). They were examined $29(n=2)$ and $31(n=2)$ months after the last treatment. The older wild bull treated for 2.5 years had successfully reversed and come into musth at that stage. Upon electro-ejaculation, he was found to have normal semen quality and an increase in serum testosterone concentration. Since this last examination, he has come into musth a second time. Although the three other bulls only showed isolated sperm present in their ejaculates, minor increases in serum testosterone concentration possibly the beginning of reversal - were observed. However,
3.5 years after the last vaccination, they still have not been in musth (unpublished data). Two wild bulls on Karongwe Game Reserve (T. Coetzee, Karongwe Game Reserve, November 2017, pers. comm.) treated with Improvac ${ }^{\circledR}$ for eight years have shown signs of behavioural reversal 18-24 months after the last treatment. The age of bulls at the time of their first treatment thus appears to influence reversibility, at least as far as androgen-dependent behaviour is concerned. Testicular Leydig cells, responsible for testosterone production, are far more resilient than spermatogenic cells. To date, testes of treated elephant bulls have not been examined histologically to determine short-, medium- or long-term effects at a cellular level.

\section{Effects of Improvac ${ }^{\circledR}$ vaccine in elephant cows \\ Induction of anoestrus in elephant cows}

The excellent results obtained with the induction of anoestrus in $100 \%$ of treated mares with Improvac $^{\circledR}$ (Botha et al. 2008) led to a trial being conducted in free-ranging elephant cows on Entabeni Game Reserve. Eight cows were treated with $600 \mu \mathrm{g}$ Improvac $^{\circledR}$ and four served as untreated controls. Before and following treatments, faecal progesterone metabolite concentrations (FPMC) were monitored to assess ovarian activity (cyclic changes in FPMC). The results were inconclusive partly because the dose of Improvac ${ }^{\circledR}$ used was too low compared to what is now used in elephant bulls $(5 \mathrm{~mL})$ and partly because the monitoring period was perhaps too short. Some of the control cows showed seasonal anoestrus during the dry season and as such the cause of anoestrus in the treated cows could not be established conclusively (Benavides Valades et al. 2012). A study of seven Asian females (Boedeker et al. 2012; Boedeker, Schmitt \& Brown 2013) resulted in suppression of the oestrus cycle. Current studies indicate that suppression of ovarian function requires more frequent and higher dosages (Boedeker et al. 2012; J. Brown, Smithsonian Institution, March 2016, pers. comm.), compared to male elephants. More recently, the successful use of another anti-GnRH vaccine (Repro-BLOC ${ }^{\circledR}$ ) to induce anoestrus in a 59-year-old Asian elephant cow for medical reasons has been reported (Boedeker et al. 2012). However, a series of treatments (primary plus four boosters) were required before the cow was finally down regulated.

TABLE 4: Results of treatment of elephant cows on four captive facilities with Improvac ${ }^{\circledR}$ to induce anoestrus.

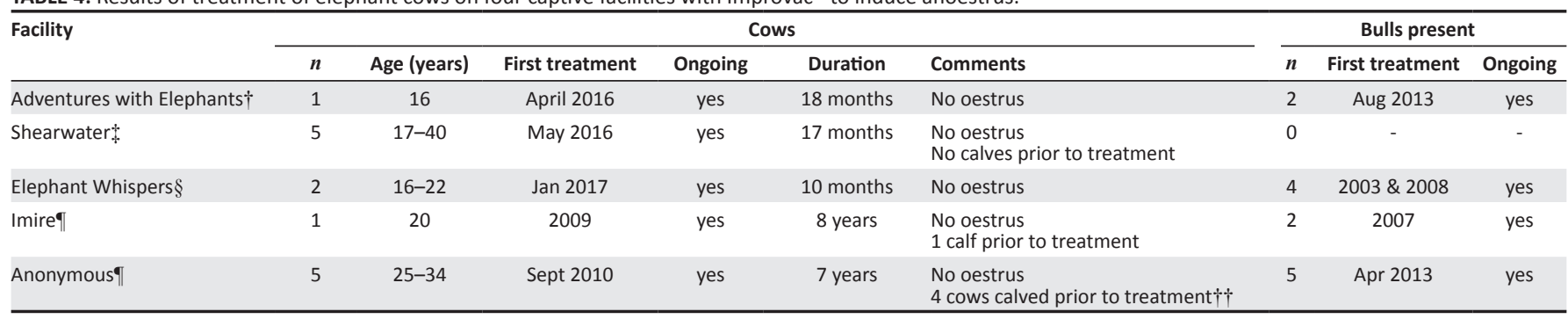

$\dagger$, Sean Hensman, Adventures with Elephants, Republic of South Africa; $\$$, Allen Roberts, Shearwater, Zimbabwe; §, Andre Kotze, Elephant Whispers, Republic of South Africa; $₫$, Reilly Travers, Imire, Zimbabwe; $\dagger$, Anonymous, Zimbabwe. 
An added indication for the use of Improvac ${ }^{\circledR}$ in captive African elephant cows in South Africa and Zimbabwe is the prevention of oestrus. According to elephant housing facilities, bulls become more difficult to handle when cows come into oestrus. In addition, breeding of calves in captivity in South Africa is mostly unwanted (National Norms and Standards for the Management of Elephants in South Africa 2008:39). There are also some facilities (Shearwater, Zimbabwe, A. Roberts) where wild and captive elephants have access to one another on the same reserve. Under such conditions, captive cows coming into oestrus can create enormous problems. Following the unsatisfactory results obtained on Entabeni, the dose of Improvac ${ }^{\circledR}$ was subsequently increased from $600 \mu \mathrm{g}$ to $1000 \mu \mathrm{g}$. Table 4 shows the numbers of cows treated on various facilities in South Africa and Zimbabwe. The increased dose applied as a primary, first booster after five weeks and then boosters every five to six months has been successful in inducing anoestrus and preventing breeding and pregnancies in all treated cows.

\section{Recommendations}

\section{Indications}

Improvac ${ }^{\circledR}$ treatment of captive elephant bulls is indicated as a means to control aggressive behaviour and musth. It is advisable to treat all post-pubertal bulls that are handled in direct contact, to avoid changes in hierarchy and to prevent younger untreated bulls from coming into musth prematurely. Until further research has been carried out, Improvac ${ }^{\circledR}$ should not be used as a contraceptive method for free-ranging elephants. From time to time, however, there is a need to control aggression or musth in free-ranging bulls. In such cases, careful consideration should be given to the bull population in the reserve and the consequences of treating some and not other bulls.

\section{Administration of Improvac ${ }^{\circledR}$ vaccine}

To limit injection site reactions, it is important to administer Improvac ${ }^{\circledR}$ by deep i.m. injection into the gluteal (dart gun from a helicopter) or semimembranous or semitendinous muscle masses. A dart gun, pole syringe or hand-injection can be used for the latter site. In the case of dart administration, a $60-\mathrm{mm}$ needle should be used. The i.m. route is preferred to subcutaneous administration for specific reasons. Irritant substances are better tolerated in the muscles; the antibody response to anti-GnRH vaccines is better when given i.m. (Dowsett et al. 1991:183-190), and, practically speaking, it is difficult to inject elephants subcutaneously. One sanctuary has been administering the vaccine by hand injection into the neck muscles behind the ear (A. Kotze, Elephant Whispers, May 2009, pers. comm.). The injection is carried out by the groom and has been done in this manner since 2008 and, once again, local swelling is sometimes observed. Only sterile equipment should be used for administrations. Bacterial contamination is likely to result in the formation of abscesses as the local oedema caused by the vaccine is an ideal medium for bacteria to thrive in.
It should be stressed that once vaccination has commenced in captive bulls, treatment should be carried out at regular intervals and with the correct dose to avoid problems. Stop-start treatments are very likely to result in a rise in serum testosterone concentrations and an increase in aggressive behaviour. This was observed on one elephant sanctuary, and as a result of his aggressive behaviour, the bull was shot (anonymous). Since this incident, all remaining bulls have been placed on regular treatments. No further incidents have been recorded since then.

\section{Reversal of Improvac ${ }^{\circledR}$ treatment}

It should be noted that medium- to long-term treatment ( $\geq 3$ years) of elephant bulls may result in permanent infertility. Permanent effects are more likely to occur in younger bulls ( $<12$ years) and especially prepubertal bulls, or after long-term regular treatments.

\section{Conclusions}

The treatment of elephant bulls with the Improvac ${ }^{\circledR}$ vaccine is able to down-regulate androgen-related behaviour and sperm production successfully in both captive and wild African elephant bulls of various ages ( $\leq 34$ years). Reversibility of these effects after medium- to long-term use is largely unknown and should be investigated. The effects of treatment on social behaviour, dominance hierarchy and movement of wild bulls also warrant more detailed studies. Treatment of peri-pubertal bulls should be discouraged owing to possible permanent suppression of reproductive organ development following repeated Improvac ${ }^{\circledR}$ administrations. Preliminary studies in cows to induce anoestrus with this vaccine appear to be successful, but require more detailed studies.

\section{Acknowledgements}

The authors would like to thank the following for their collaboration and providing information: Adventures with Elephants (Limpopo Province), Elephant Whispers (Mpumalanga Province), Imire Wildlife and Conservation (Zimbabwe), Karongwe Game Reserve (Limpopo Province), Shearwater (Zimbabwe) and Dr Mike Toft. Funding for this study was provided by the following: University of Pretoria, International Elephant Fund, United States Fish and Wildlife Services, Technology Innovation Agency and Birmingham Zoological Gardens.

\section{Competing interests}

There are no competing interests with regard to the writing of this article.

\section{Authors' contributions}

H.J.B. wrote the article, and I.L. reviewed and contributed to the writing up of the article. 


\section{References}

Bertschinger, H., Delsink, A., Van Altena, J.J., Kirkpatrick, J., Killian, H., Ganswindt, A. et al., 2008, 'Chapter 6: Reproductive control of elephants', in R.J. Scholes \& K.G. Mennel (eds.), Elephant management: A scientific assessment for South Africa, pp. 257-328, Wits University, Press, Johannesburg, South Africa.

Bertschinger, H.J., Delsink, A., Kirkpatrick, J.F., Van Altena, J.J., Denys, H., Bates, M. et al., 2009, 'Immunocontrol of reproductive rate and aggression in African elephants', in British Veterinary Zoological Society, York, November 7-8, p. 71.

Bertschinger, H.J. \& Sills, E.S., 2013, 'Contraceptive applications of GnRH-analogs and vaccines for wildlife mammals of southern Africa: Current experience and future challenges', in E.S. Sills (ed.), Gonadotropin-releasing hormone (GnRH). Production, structure and function, pp. 85-107, Nova Science Publishers Inc. New York, (eBook).

Benavides Valades, G., Ganswindt, A., Annandale, H., Schulman, M.L. \& Bertschinger, H.J., 2012, 'Non-invasive assessment of the reproductive cycle in
free-ranging female African elephants (Loxodonta africana) treated with a free-ranging female African elephants (Loxodonta africana) treated with a
gonadotropin-releasing hormone $(\mathrm{GnRH})$ vaccine for inducing anoestrus', gonadotropin-releasing hormone (GnRH) vaccine for inducing anoestrus',
Reproductive Biology and Endocrinology 10, 63. https://doi.org/10.1186/14777827-10-63

Birrell, R.J., 2017, 'Vaccination against GnRH as a prelude to surgical castration of horses', MSc thesis, Department of Production Animal Studies, Faculty of horses', MSc thesis, Department of Production
Veterinary Science, University of Pretoria, pp. 1-49.

Boedeker, N., Schmitt, D. \& Brown, J., 2013, 'GnRH vaccination as a treatment for reproductive tract pathologies in female elephants (contraception for postreproductive cows? Why close the door after the cow is out?)', in Proceedings of reproductive cows? Why close the door after the cow is out?), in Proceedings of
the International Elephant and Rhino Conservation and Research Symposium, the International Elephant and Rhino
Pittsburgh, PA, August 26-30, p. 30.

Boedeker, N.C., Hayek, L.-A.C., Murray, S., De Avila, D.M. \& Brown, J.L., 2012, 'Effect of a gonadotropin-releasing hormone vaccine on ovarian cyclicity and uterine morphology of an Asian elephant (Elephas maximus)', Journal of Zoo Wildlife morphology of an Asian

Botha, A.E., Schulman, M.L., Bertschinger, H.J., Guthrie, A.J., Annandale, C.H. \& Hughes, S.B., 2008, 'The use of a GnRH vaccine to suppress mare ovarian activity in a large group of mares under field conditions', Wildlife Research $35,548-554$.

Curtis, P.D., Richmond, M.E., Miller, L.A. \& Quimby, F.W., 2008, 'Physiological effects of gonadotropin-releasing hormone immunocontraception on white-tailed deer', Human-Wildlife Conflicts 2(1), 68-79.

De Nys, H.M., Bertschinger, H.J. \& Human, A., 2003, 'Control of testosterone secretion, musth and aggressive behaviour in African elephant (Loxodona africana) bulls using a GnRH vaccine', in Proceedings of the 19th Faculty Day of the Faculty of Veterinary Science, Onderstepoort, University of Pretoria, September 25, p. 17.

De Nys, H.M., Bertschinger, H.J., Turkstra, J.A., Colenbrander, B., Palme, R. \& Human A.M., 2010, 'Vaccination against GnRH may suppress aggressive behaviour and musth in African elephant (Loxodonta africana) bulls - A pilot study', Journal of the South African Veterinary Association 81, 8-15.

De Oliveira, C.A., West, G.D., Houck, R. \& Leblanc, M., 2004, 'Control of musth in an Asian elephant bull (Elephas maximus) using leuprolide acetate', Zoo and Wildlife Medicine 35, 70-76.

D'Occhio, M.J., 1993, 'Immunological suppression of reproductive functions in male and female mammals', Animal Reproduction Science 33, 345-372.

Doughty, L.S., Slater, K., Zitzer, H, Tomos Avent, H. \& Thompson, S., 2014, 'The impact of male contraception on dominance hierarchy and herd association patterns of African elephants (Loxodonta africana) in a fenced game reserve', Global Ecology African elephants (Loxodonta

Dowsett, K.F., Knott, L.M., Tshewang, U., Jackson, A.E., Bodero, D.A.V. \& Trigg, T.E., 1996, 'Suppression of testicular function using two dose rates of a reversible water soluble gonadotrophin releasing hormone (GnRH) vaccine in colts', water soluble gonadotrophin releasing

Dowsett, K.F., Pattie, W.A., Knott, L.M., Jackson, A.E., Hoskinson, R.M., Rigby, R.P.G. et al., 1991, 'A preliminary study of immunological castration in colts', Journal of Reproduction and Fertility Supplement 44, 183-190.

Dunshea, F.R., Colantoni, C., Howard, K., Mc Cauley, I., Jackson, P., Long, K.A. et al., 2001, 'Vaccination of boars with GnRH vaccine (Improvac) eliminates boar tain and increases growth performance', Journal of Animal Science 79, 2525-2535.

Eisenberg, J.F., McKay, G.M. \& Jainudeen, M.R., 1971, 'Reproductive behavior of the Asiatic elephant (Elephas maximus maximus L.)', Behaviour 38, 193-225.

Ferro, V.A., Khan, M.A.H., McAdam, D., Colston, A., Aughey, E., Mullen, A.B. et al., 2004, 'Efficacy of an anti-fertility vaccine based on mammalian gonadotrophic releasing hormone(GnRH-1) - A histological comparison in male animals', Veterinary Immunology and Immunopathology 101, 73-86.

Ganswindt, A., Heistermann, M., Borragan, S. \& Hodges, J.K., 2002, 'Assessment of testicular endocrine function in captive African elephants by measurement of urinary and faecal androgens', Zoo Biology 21, 27-36.

Ganswindt, A., Muenscher, S., Henley, M., Henley, S., Heistermann, M., Palme, R. et al., 2010, 'Endocrine correlates of musth and the impact of ecological and social factors in free-ranging African elephants (Loxodonta africana)', Hormones and factors in free-ranging
Behaviour 57, 506-514.
Ghoneim, I.M., Waheed, M.M., Al-Eknah, M.M. \& El-Bahr, S.M., 2012, 'Immunization against GnRH in the male camel (Camelus dromedaries): Effects on sexual behaviour, testicular volume, semen characteristics and serum testosterone behaviour, testicular volume, semen characterist
concentrations', Theriogenology 78, 1102-1109.

Godfrey, S.I., Walkden-Brown, S.W., Martin, G.B. \& Speijers, E.J., 1996, 'Immunisation of goat bucks against GnRH to prevent seasonal reproductive and agonistic behaviour', Animal Reproduction Science 44, 41-54

Hollister-Smith, J.A., Poole, J.H. \& Archie, E.A., 2007, 'Age, musth and paternity success in wild male African elephants, Loxodonta africana', Animal Behaviour 74, 287-296.

Janett, F., Lanker, U., Jorg, M., Hassig, M. \& Thun, R., 2003, 'Castration of male lambs by immunisation against GnRH', Schweizer Archiv für Tierheilkunde 145, 291-299.

Janett, F., Stump, R., Burger, D. \& Thun, R., 2009, 'Suppression of testicular function and sexual behaviour by vaccination against $\mathrm{GnRH}$ (Equity ${ }^{\mathrm{TM}}$ ) in the adult stallion', Animal Reproduction Science 115, 88-102.

Kaewmanee, S., Watanabe, G., Keio, M., Kishimoto, M., Jin, W.Z., Yamamoto, Y. et al., 2011, 'A surge-like increase in luteinizing hormone preceding musth in a captive bull African elephant (Loxodonta africana)', Journal of Veterinary Medical Science 73, 379-383.

Kauffman, A.S., 2004, 'Emerging functions of gonadotropin-releasing hormone II in mammalian physiology and behaviour', Journal of Neuroendocrinology 16, 794-806.

Killian, G., Miller, L., Rhyan, J. \& Doten, H., 2006, 'Immunocontraception of Florida feral swine with a single dose GnRH vaccine', American Journal of Reproductive Immunology 55, 378-384.

Lee, P.C. \& Moss, C.J., 1995, 'Statural growth in known-age African elephants (Loxodonta africana)', Journal of Zoology 236, 29-41.

Levy, J.K., Miller, L.A., Crawford, P.C., Ritchley, J.W., Ross, M.K. \& Fagerstone, K.A., 2004, 'GnRH immunocontraception of male cats', Theriogenology 62, 1116-1130.

Lueders, I., Hildebrandt, T.B., Gray, C., Botha, S., Rich, P. \& Niemuller, C., 2014, 'Suppression of testicular function in a male Asian elephant (E. maximus) treated with gonadotropin releasing vaccines', Journal of Zoo and Wildlife Medicine 45(3), 611-619.

Lueders, I., Young, D., Botha, S., Gray, C., Luther, I., Maree, L. et al., 2013, 'Suppression of testicular function by means of a GnRH vaccine in African elephant bulls', in Proceedings of the International Elephant and Rhino Conservation and Research Symposium, Pittsburgh, PA, August 26-30, pp. 31-33.

Lueders, I., Young, D., Maree, L., Van der Horst, G., Luther, I., Botha, S. et al., 2017, 'Effects of $\mathrm{GnRH}$ vaccination in wild and captive African elephant bulls (Loxodonto africana) on reproductive organs and spermatogenesis', PLoS One 12(9), e0178270, 1-21. https://doi.org/10.1371/journal.pone.0178270

Malmgren, L., Andresen, O. \& Dalin, A.M., 2001, 'Effects of GnRH immunisation on hormone levels, sexual behaviour, semen quality and testicular morphology in mature stallions', Equine Veterinary Journal 33, 75-83.

Miller, L.A., Johns, B.E. \& Killian, G.J., 2000, 'Immunocontraception of white tailed dee with GnRH vaccine', American Journal of Reproductive Immunology 44, 266-274.

Miller, L.A., Rhyan, J.C. \& Drew, M., 2004, 'Contraception of bison by GnRH vaccine: A possible means of decreasing transmission of brucellosis in bison', Journal of Wildlife Diseases 40, 725-730.

National Norms and Standards for the Management of Elephants in South Africa, 2008, National Environmental Management: Biodiversity Act, 2004 Government Gazette (Act no. 10 of 2004), Government Printers, Pretoria.

Niemuller, C.A., Brown, J.L. \& Hodges, J.K., 1998, 'Reproduction in elephants', in E. Knobil \& J.D. Neill (eds.), Encyclopedia of reproduction, pp. 1018-1029, Academic Press, New York.

Palme, R. \& Möstl, E., 1994, 'Biotin-streptavidin enzyme immunoassay for determination of oestrogens and androgens in boar faeces', in S. Görög (ed.), Advances of steroid analysis '93', pp. 111-117, Akadémiai Kiadó, Budapest.

Schulman, M.L., Botha, A.E., Muenscher, S.B., Guthrie, A.J., Bertschinger, H.J., 2012, 'Reversibility of the effects of GnRH vaccination used to suppress reproductive function in mares', Equine Veterinary Journal ISSN 0425-1644, DOI: 10.1111/j.2042-3306.2012.00577

Shrader, A.M., Ferreira, S.M., McElveen, M.E., Lee, P.C., Moss, C.J. \& Van Aarde R.J., 2006, 'Growth and age determination of African savannah elephants', Journal of Zoology 270, 40-48.

Somgird, C., Homkong, P., Sripiboon, S., Brown, J.L., Stout, T.A., Colenbrander, B. et al., 2016, 'Potential of a gonadotropin-releasing hormone vaccine to suppress musth in captive male Asian elephants (Elephas maximus)', Animal Reproduction Science 164, 111-120.

Theubet, G., Thun, R., Hilbe, M. \& Janett, F., 2010, 'Wirkung einer Impfung gegen GnRH (Bopriva") beim männlichen pubertären Kalb', Schweizer Archiv für Tierheilkunde 152(10), 459-469.

Turkstra, J.A. Van der Meer, F.J.U.M., Knaap, J., Rottier, P.J.M., Teerds, K.J, Colenbrabder, B et al. 2005, 'Effects of GnRH immunization in sexually mature pony stallions', Animal Reproduction Science 86, 247-259.

Yu, Y.Z. \& Shi, J.X., 2009, 'Relationship between levels of testosterone and cortisol in saliva and aggressive behaviors of adolescents', Biomedical and Environmental Sciences 22(1), 44-49. 